\title{
Literatura na Educação Infantil: modos de trabalho com textos e possibilidades do desenvolvimento da capacidade criativa
}

\section{Literature and Children Education: ways to work with texts and possibilities to develop creative skills}

https://doi.org/10.34112/2317-0972a2016v34n68p45-64

\section{Larissa Elizabeth Barros Brito ${ }^{1}$}

Maria Sílvia Pinto de Moura Librandi da Rocha ${ }^{2}$

Resumo: Apresentam-se resultados de pesquisa desenvolvida junto a uma turma de Educação Infantil, com objetivo de investigar as formas de trabalho pedagógico com a literatura infantil, perscrutando seus possíveis efeitos no desenvolvimento da capacidade criativa das crianças. A pesquisa foi realizada através dos seguintes procedimentos metodológicos: (i) entrevistas semiestruturadas com a professora da turma e com a bibliotecária da escola; (ii) observação das leituras de histórias; e (iii) entrevista semiestruturada em grupo com as crianças. Todos os procedimentos foram videofilmados; parte das entrevistas com as crianças foi também audiogravada. As análises realizadas foram qualitativas, com especial destaque para o material empírico produzido nas entrevistas com as crianças, contrastado com as (im) possibilidades de desenvolvimento criativo a partir do trabalho com apostilas. Os resultados apontam para distintas formas de elaboração das crianças sobre e a partir de histórias narradas e permitem identificar práticas pedagógicas e o lugar da literatura infantil nas escolas.

PALAVRAS-CHAVE: Literatura infantil; educação infantil; capacidade criadora.

1. Pontifícia Universidade Católica de Campinas, Campinas, SP, Brasil.

2. Pontifícia Universidade Católica de Campinas, Campinas, SP, Brasil. 
ABSTRACT: These are the outcomes of a research developed with a classroom in Children Education, aiming at investigating how to work pedagogically with children's literature by scrutinizing their possible effects on children's creative skill development. The research was conducted under the following methodologic procedures: (i) structured interview with the classroom's teacher and the school's librarian; (ii) observation of story tellings; and (iii) semi-structured group interview with the children. All the procedures were recorded in video; the audio was recorded in part of the interview with the children. Qualitative analyses were applied, with special focus on the empirical material produced during the interview with the children, by contrasting the creative development (im)possibilities when working with textbooks. The results show different child developments based on the narrated stories and they allow us to identify pedagogical practices and the scope of children's literature in schools.

KEYWORDS: Children's literature; child education; creative skills.

\section{INTRODUÇÃO}

Quando se pensa em práticas pedagógicas na Educação Infantil, dificilmente a literatura infantil ficará de fora. O livro infantil tem sido considerado como um material a partir do qual a criança pode ser estimulada a imaginar, recordar, conhecer e experienciar situações nunca antes vividas. E, a partir delas e das (re)significações que faz delas, criar. Através da literatura, a criança pode ampliar suas relações com o mundo exterior e também tomar consciência sobre seus próprios sentimentos e pensamentos. "Encantamento", "fascinação", "experiências surpreendentes" têm sido palavras corriqueiramente associadas - no senso comum, mas também na literatura científica - com esse tipo de produção cultural. Entretanto, não podemos dizer que o livro, por si só, garante esse possível encantamento e estímulo à imaginação. $\mathrm{O}$ adulto que ocupa o papel de mediador entre o livro e a criança é parte fundamental para a escolha do modo como irão lidar com o livro, com o texto, com a história, com as imagens. É nas relações sociais que a criança começa a ter contato com as práticas de leitura e se apropria delas.

A leitura pode ser trabalhada de diferentes formas na escola, e o professor, perante o texto, pode também assumir diferentes posições, de acordo com suas concepções de literatura e criança e com seus objetivos para a turma com que trabalha. A mediação do professor influi e afeta de diferentes maneiras as crianças envolvidas, 
e essa mediação se modaliza segundo a intenção que ele tem nas interações que estabelece com seus alunos.

\section{Modos De USO Do TEXTO NA ESCOLA}

Geraldi (2002) apresenta quatro modos mais típicos de trabalho pedagógico com a leitura: a leitura busca de informações, a leitura estudo do texto, a leitura do texto como pretexto e a leitura fruição do texto. A leitura busca de informações tem como objetivo principal responder perguntas já estabelecidas a título de interpretação, ou seja, tendendo a ser uma simulação da leitura. Tal prática se torna menos artificial quando é explicitado um "para quê" extrair tais informações. Questionamentos que vão além da questão da leitura, como afirma Geraldi (2002, p. 93): "Responder o 'para quê' ler um texto, buscando nele informações, é uma questão prévia não só desse 'tipo' de leitura, mas de toda a atividade de ensino: ensinamos para quê? Os alunos aprendem para quê?". O aluno pode, então, ler um texto a fim de responder a perguntas já estabelecidas, sem saber exatamente o "para quê" disso e, neste caso, extrai informações superficiais do que lê; quando está ciente das razões desse trabalho, pode ler um texto com o objetivo de extrair informações e elaborá-las de formas mais profundas.

A leitura estudo do texto acompanha o seguinte roteiro: tese defendida no texto, argumentos levantados a favor da tese, contra-argumentos e coerência entre tese e argumentos. Certamente, esses tópicos podem se desdobrar em outros no processo de estudar o texto lido. No texto literário, Geraldi (2002, p. 96) exemplifica indicando que "podem-se 'estudar' narrativas, verificar pontos de vista defendidos por personagens e contrapostos por outros etc."

O texto como pretexto pode aparecer de duas formas: ao se propor uma atividade a partir da leitura de um texto, este pode ficar secundarizado ou mesmo desaparecer durante a execução daquilo que é proposto. Nesse caso, não se valoriza o texto, mas, sim, o objetivo da segunda atividade. Outra forma de trabalhar o texto como pretexto é desdobrando atividades a partir da leitura. É possível, entre várias outras possibilidades, transformar a leitura numa dramatização, ilustrar determinada história, produzir outro texto a partir do que se leu. Nesses casos, o texto pode ser valorizado na produção das atividades conseguintes.

Diferentemente dos três primeiros modos, a leitura como fruição não tem como preocupação o controle dos resultados do ato de ler; trata-se de construir/ 
conservar/intensificar o prazer no processo. Numa sociedade capitalista, na qual o produto final de uma atividade importa, pensar na fruição parece algo de difícil concretização. Habitualmente, os professores questionam como irão avaliar o aluno a respeito de uma leitura - ou mesmo como saberão que o aluno leu o texto -, se não solicitarem uma ficha, desenvolverem perguntas ou aplicarem uma prova (GERALDI, 2002).

Nas leituras realizadas pelo cidadão "comum" (nas condições de não aluno ou de não professor), predomina a leitura fruição. Se a leitura fruição ainda é marginalizada na sala de aula, segundo Geraldi (2002, p. 98), "recuperar na escola e trazer para dentro dela o que dela se exclui por princípio - o prazer - [nos] parece o ponto básico para o sucesso de qualquer esforço honesto de 'incentivo à leitura'”. Para recuperar o prazer pela leitura, o autor vê a necessidade de resgatar princípios das nossas vivências de leitores. Segundo Cruz (2002), em primeiro lugar, para que o aluno se encante com a leitura, é importante que o professor seja um bom leitor, indique leituras e mostre entusiasmo, ao levar um livro a seus alunos (embora consentindo que apenas o entusiasmo não é suficiente para que o professor desenvolva atividades que priorizem o processo da leitura).

Dessa forma, podemos dizer que as inúmeras possibilidades de trabalho com a leitura estão nas condições de produção em que ela é realizada, como ressaltam Fonseca e Geraldi (2002, p. 108) no trecho a seguir:

A multiplicidade de leituras que um mesmo texto pode ter não nos parece resultado do próprio texto em si, produzido em condições específicas, mas sim resultado dos múltiplos sentidos que se produzem nas diferentes condições de produção de leitura. Em cada leitura, mudadas as condições de sua produção, temos novas leituras e novos sentidos por elas produzidos. Assim, ainda que o interlocutor-leitor seja o mesmo, mudados os objetivos de sua leitura, estarão alteradas as condições de produção e, portanto, o processo.

A literatura infantil pode desempenhar um papel ainda mais positivo quando o uso do texto pode ser diversificado, ou seja, quando cada criança é estimulada a construir suas significações entretecidas com o texto, a partir de suas experiências, incorporando-as em seu modo de pensar, sentir e agir.

Segundo Silva (2002), lê-se muito pouco na escola; em geral, os professores mantêm um "ritual" que permite duas a quatro leituras por ano e com o único 
objetivo de produzir um material avaliativo do aluno. São os chamados "livros obrigatórios", escolhidos pelo professor, num processo em que não se podem aceitar sugestões ou acatar os interesses de quem vai lê-los: os alunos. Portanto, é possível afirmar que na escola costuma predominar um trabalho artificial com a literatura, composto por simulações de leitura.

Consideramos as elaborações de Geraldi (2002) e Silva (2002) de extrema importância, mas ressaltamos que foram formuladas tendo em perspectiva os níveis do Ensino Fundamental e Médio. Sendo assim, nos dispusemos a examinar práticas pedagógicas com a literatura na Educação Infantil, analisando-as a partir destas categorias e com especial interesse em identificar possibilidades de desenvolvimento da imaginação para as crianças que delas participam. Para realizar esta intenção, iniciamos com uma revisão bibliográfica que nos permitisse construir um panorama mais amplo, referente aos modos pelos quais o tema tem se constituído como objeto de estudos científicos.

\section{REVISÃO DA LITERATURA}

Para a revisão bibliográfica tomamos como fonte de consulta o portal de periódicos da Coordenação de Aperfeiçoamento de Pessoal de Nível Superior (CAPES) e o site Scientific Eletronic Library Online (SCIELO). Em ambos os portais utilizamos o descritor "Literatura Infantil" (entre aspas, para trabalharmos com o termo exato). Posteriormente, utilizando filtros dentro de nosso campo de interesse, compusemos um conjunto de 37 trabalhos (entre artigos, teses e dissertações) ${ }^{3}$.

Os trabalhos selecionados foram categorizados quanto aos procedimentos metodológicos de pesquisa, o que permitiu verificar uma maior produção de pesquisas que realizaram análise de documentos. Entrevistas e observações, apesar de aparecerem em menor frequência, em sua maioria elegeram crianças como participantes. No total foram verificadas seis pesquisas com entrevistas (ou procedimentos

3. Na SCIELO, no filtro Coleções, selecionamos Brasil e no filtro Tipo de literatura, selecionamos Resultado de Pesquisa, obtendo, assim, 32 artigos. No portal da CAPES foram utilizados os filtros Periódicos revisados por pares e Português, resultando em 16 artigos. A partir da leitura dos títulos e dos resumos foram descartados 8 artigos da pesquisa CAPES, sendo 7 por apresentarem foco em dramatização, letras de músicas infantis e/ ou por não serem pesquisas da bibliografia nacional e um por também aparecer na pesquisa feita na Scielo; nesta base foram descartados 3 artigos, por serem trabalhos da área da saúde e/ou não serem pesquisas da bibliografia nacional. 
similares) com crianças - e em três delas também se realizou observação com a presença de crianças - e apenas uma com egressas do curso de pedagogia. As informações sobre os procedimentos metodológicos foram retiradas do próprio resumo dos trabalhos analisados.

O segmento educacional abordado não foi o mesmo para todas as pesquisas: uma delas investigou os últimos anos do Ensino Fundamental (XAVIER FILHA, 2011); quatro focalizaram primeiros anos do Ensino Fundamental (ALMEIDA; GOMES; MONTEIRO, 2013; ARENA; LOPES, 2013; MONTEIRO, 2010; PORCACCHIA; BARONE, 2011); e cinco pesquisas elegeram a Educação Infantil como campo (OLIVEIRA; CALDIN; SILVA, 2006; PRADO, 2012; RODRIGUES; HENRIQUE; PATRÍCIO, 2009; SILVA; SOUZA, 2013; WITTER; RAMOS, 2008). Em nenhum deles encontramos análises sobre os diversos modos pelos quais os textos de literatura podem ser incorporados nas práticas pedagógicas cotidianas da Educação Infantil, o que nos permite destacar a importância de nossa própria pesquisa.

\section{ENTRANDO NA ESCOLA}

O locus do trabalho investigativo foi uma escola particular de uma cidade do interior de São Paulo, frequentada por 1010 alunos de 2 a 18 anos, pertencentes a famílias de classe média a classe média alta e provenientes de diversos bairros do município. Desse total, 215 estão na Educação Infantil. É possível perceber que, tanto pelas instalações físicas, quanto pelo cuidado com questões pedagógicas, a escola dá significativa atenção à Educação Infantil: equipa o espaço com parques, área de piscina, áreas gramadas, campo, biblioteca e áreas criadas especialmente para as crianças deste segmento.

Em busca de alcançarmos nosso objetivo, adentramos uma sala de aula de PréII, composta por 19 crianças de 5 e 6 anos (11 meninos e 8 meninas) 4 . A pesquisa foi realizada através dos seguintes procedimentos metodológicos: (i) entrevista semiestruturada com a professora da turma e a bibliotecária da escola; (ii) observação das

4. O primeiro passo para realização da pesquisa foi sua submissão ao Comitê de Ética em Pesquisa com Seres Humanos da PUC-Campinas (CAAE: 34723414.8.00oo.5481). Após aprovação pelo referido Comitê e a assinatura dos Termos de Consentimento Livre e Esclarecido pela professora responsável pela turma do Pré II, pela bibliotecária e pelos pais ou responsáveis dos alunos da turma, iniciamos a pesquisa de campo. 
leituras de histórias; e (iii) entrevista semiestruturada em grupo com as crianças. Todos os procedimentos foram videofilmados; partes das entrevistas com as crianças foram também audiogravadas.

O TRABALHO COM LITERATURA INFANTIL

O trabalho com a literatura infantil da turma de Pré-II, segundo nos informou a professora da turma, Neusa ${ }^{5}$, ocorre em três momentos: o Projeto Leitura, as leituras indicadas pela apostila e as leituras na biblioteca.

O Projeto Leitura acontece de dois modos diferentes ao longo do ano. No primeiro, nas sextas-feiras, as crianças levam para casa livros da biblioteca que elas mesmas escolheram dentre aqueles designados para a Educação Infantil. Orienta-se que os pais leiam com os filhos a história durante o final de semana; na segunda-feira conseguinte, os alunos contam-na a um colega da turma. No segundo semestre este esquema é mantido; além dele, os alunos também trabalham com livros comprados pelos pais, preestabelecidos pela escola; a partir dessa leitura os alunos devem realizar uma atividade.

O segundo momento são as leituras indicadas pela apostila, normalmente realizadas pela professora e, eventualmente, pela bibliotecária. São indicados dois livros por apostila, relacionados com eixos temáticos diferenciados. Por exemplo, o tema da apostila quatro, na qual consta a indicação do livro $A$ escolinha do mar, de Ruth Rocha (abordado mais à frente, neste texto) é "Céu, mares e rios". A apostila começa com conteúdos como "O Planeta Azul"; "De onde vem a chuva?"; "A vida no mar"; "A vida nos rios"; "Água é vida" e somente na última sessão indica a "Hora da história”, com o livro já citado. Em seguida à indicação, apresenta-se a seção "Trocar ideias", na qual os autores do material levantam questões sobre o livro; atividades complementares finalizam a unidade. A professora conta que, após a leitura, também costuma pedir um desenho, feito pelos alunos no caderno de Arte.

$\mathrm{O}$ último momento de trabalho com a literatura são as leituras na biblioteca, feitas pela bibliotecária Carina, com livros que ela ou a professora escolhem, seguidas de vídeo de desenho animado com tema semelhante ao da leitura realizada.

5. Todos os nomes são fictícios. 
Além dos três momentos de leitura, a professora disponibiliza aos alunos gibis, que podem ser "lidos" quando terminam as atividades da apostila. Segundo Neusa, as crianças gostam bastante desse momento.

A partir dessas informações, identificamos que, na turma, três dos quatro modos de trabalho com textos literários apontados por Geraldi (2002) são colocados em funcionamento. Com a diversidade das atividades busca-se contemplar a leitura busca de informações (por exemplo, nas perguntas feitas a partir do que se propõe na apostila e nas perguntas que observamos a professora fazer, ao ler o livro $A$ escolinha do mar), a leitura do texto como pretexto (por exemplo, nas atividades complementares propostas pela apostila) e a leitura fruição do texto (com especial destaque para as "leituras" de gibis e para as da bibliotecária). Apenas a leitura estudo do texto não parece sistematicamente trabalhada, provavelmente pela idade das crianças.

Como nosso objetivo neste artigo é examinar práticas pedagógicas com a literatura na Educação Infantil, com especial interesse em identificar possibilidades de desenvolvimento da imaginação para as crianças que delas participam, passaremos a apresentar a atividade em que mais ações criativas foram registradas: os momentos de produção de desenhos no desenrolar das entrevistas. Considerando que esses momentos têm afinidades estruturais com o trabalho pós-leitura de textos proposto pela apostila (no sentido de serem atividades realizadas tendo o texto como pretexto), colocaremos, posteriormente, em contraste essas duas propostas. A seguir, descrevemos as entrevistas.

\section{As entrevistas}

Foram realizadas 18 entrevistas semiestruturadas, com grupos compostos por dois a cinco alunos. As entrevistas em grupo priorizaram valorizar as interações (crianças com outras crianças e crianças com a pesquisadora) durante o seu desenrolar; em alguns encontros também utilizamos gravação em áudio (o gravador permanecia próximo da pesquisadora e das crianças ou passava pelas mãos das crianças enquanto contavam o que se lembravam das histórias). Durante os encontros as crianças e a pesquisadora sentavam-se no chão da sala. Embora os registros tenham sido assistidos e ouvidos integralmente, sucessivas vezes, as transcrições foram seletivas, pois elegemos, da filmagem total, os episódios mais produtivos para análises qualitativas. Além das falas das crianças, 49 desenhos feitos por elas durante as entrevistas também foram objeto de análises. 
Todas as entrevistas tiveram como ponto de partida a história contada naquele dia. Longe de uma padronização, essas entrevistas buscaram caminhar a partir do que o campo ia mostrando, ou seja, do que as crianças iam falando, das informações e das lembranças que traziam à tona. Os encontros apresentavam o seguinte formato básico: perguntas sobre a história, produções de desenhos e comentários sobre o que desenharam. Em todas as entrevistas, porém, muitos outros assuntos foram sendo tematizados. Iniciávamos a conversa perguntando às crianças se tinham ido à biblioteca e qual história haviam escutado; depois outras questões eram levantadas, a fim de ampliar a compreensão sobre suas apreciações a respeito da história e os modos como a tinham entendido.

Após esse momento, propúnhamos às crianças que fizessem um desenho, tendo como referência a história; as crianças elegiam livremente o que queriam desenhar. Embora conversássemos durante todo o encontro, após finalizarem os desenhos, as crianças eram estimuladas a comentá-los com a pesquisadora e com os colegas.

Todas as enunciações eram acolhidas como possíveis, sem censuras, sem certo ou errado, o que permitia que as crianças se sentissem bem à vontade para dizer o que pensavam. Ser flexível como entrevistador, quando se trata de uma pesquisa com crianças, é essencial.

Dentro da perspectiva Histórico-cultural, entendemos a entrevista como um momento de relação social no qual pesquisador e pesquisado têm participação ativa na construção de significações sobre o objeto cultural focalizado nessa atividade (as histórias contadas). É um processo dinâmico no qual as enunciações dos participantes são passíveis de transformações e desenvolvimento a partir das experiências que vivem, das que se recordam e das que vivem a partir das memórias do outro (FREITAS, 2007).

Com o trabalho analítico, encontramos tendências de elaborações por parte das crianças: (i) narrativas que recontavam a história lida, (ii) discussões nas quais os participantes colocavam pontos de vista ou opiniões, (iii) relatos de experiências pessoais e (iv) narrativas (re)inventadas. Em função de nosso objetivo, focalizaremos o último eixo.

Porque é CaIXa Da IMAginaÇão: NarRativas inventadas

Além do que lembravam das histórias lidas, além da parte de que mais gostaram, ou do personagem que se destacou em suas memórias, as crianças manifestaram 
grande interesse pela criação, por inventar, principalmente no momento de produção do desenho. Conforme já apontamos, nos aportes sobre a literatura infantil destaca-se, frequentemente, seu papel na constituição da imaginação, sua potencialidade para provocar sentidos inesperados. Mas, no caso de nossa investigação, essa dinâmica se mostrou especialmente possível não no momento em que ouviam e/ou falavam sobre o texto, e sim no processo dinâmico da produção dos desenhos. Ao reler as transcrições, foi possível verificar a considerável quantidade de vezes em que a ideia de "inventar" se repete, ora sinalizada pelas crianças, ora pela pesquisadora. As crianças perguntavam se poderiam inventar uma parte da história e gostavam de acrescentar elementos novos nos desenhos, como pode ser observado no trecho a seguir:

Vicenzo descreve o que desenhou.

Vicenzo: Sabe o que é isso vermelho, tia?

Pesq.: $O$ quê?

Vicenzo: Eu inventei. É um rádio de música.

Pesq.: Um rádio de música no navio? Legal, hein? Agora ficou divertido o navio pirata. (Entrevista o11)

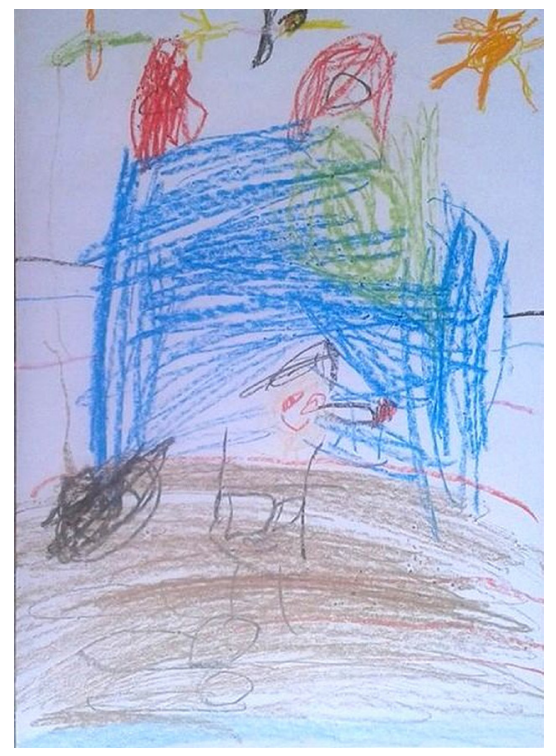

Figura o1: Desenho de Vicenzo: livro A caixa surpresa. Fonte: Arquivos da pesquisadora. 
Vicenzo desenha o navio pirata, elemento da história, e nesse mesmo navio ele acrescenta algo novo, deixando-o "divertido". Nesta entrevista, especialmente, a ideia da invenção aparece várias vezes:

Pesq.: O que tinha nesse desenho, Rafael?

Rafael: Eu desenhei um navio pirata, o mar, uma bruxa...

[...]

Pesq.: E essas cores que você misturou aqui no Sol?

Rafael: A...

Vicenzo interrompe: É o pôr do Sol!

Pesq.: Vicenzo, deixa ele falar.

Rafael: É.É o Sol que eu inventei. Porque é caixa de imaginação. (Entrevista o11)

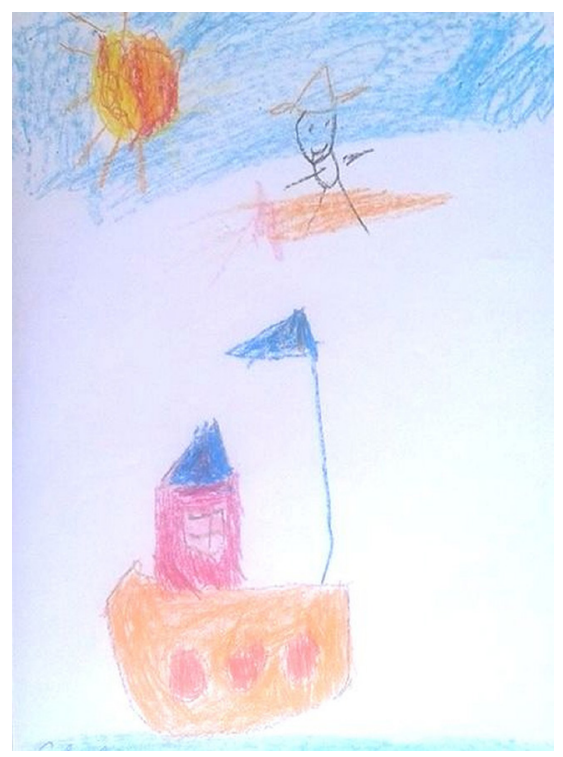

Figura 02: Desenho de Rafael: livro A caixa surpresa.

Fonte: Arquivos da pesquisadora.

Em seu desenho, Rafael não destaca um elemento propriamente inovador, mas suas justificativas quanto ao modo de pintura o tornam uma criação, o que é permitido, segundo ele, porque se trata de uma história sobre uma "caixa da imaginação". Luise segue, mantendo a ideia de invenção. Quando pergunto o que ela desenhou, responde: 
Literatura na Educação Infantil: modos de trabalho...

Luise: Foi uma bruxa que eu inventei que eu vi na propaganda do halloween. Que tem na minha sapatilha. Dá medo de desenhar ela, a outra bruxa, que ela é feia.

Pesq.: Qual é feia?

Luise: $A$ do livro.

$[\ldots]$

Pesq.: Olha... Então você inventou uma bruxa nova? (Entrevista o11)

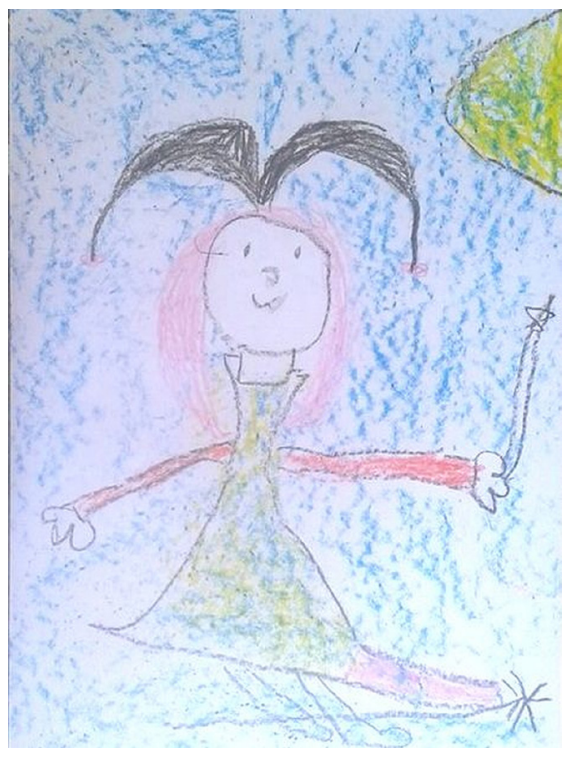

Figura 03: Desenho de Luise: livro A caixa surpresa. Fonte: Arquivos da pesquisadora.

No desconforto com a bruxa da história do livro, Luise "inventa" outra bruxa, baseando-se no que já viu, "na propaganda do halloween".

No episódio a seguir destacado, Nívia cria um monstro novo a partir da leitura do livro Domador de monstros, afirmando ser a sua, a verdadeira história:

Pesq.: Nívia, conta o que você desenhou?

Nívia: A verdadeira história da história, é que o monstro... Ninguém sabe onde tá o rosto dele.

Pesq.: Não tem rosto seu monstro?

Nívia confirma.

Pesq.: E quantas pernas ele tem?

Nívia: Quatro. 
Pesq.: Que mais ele tem?

Nívia: Oito trombas.

Pesq.: Oito trombas? E que mais?

Nívia: Cinco "bigos".

Pesq.: Cinco umbigos?

Nívia: Sete olhos.

Pesq.: Que mais?

Nívia: É... Dois chifres! De touro.

Pesq.: Dois chifres? E onde ele mora?

Nívia: Numa caverna.

Pesq.: Numa caverna?

Nívia: Ele mora dentro de uma caveira!

Pesq.: Uma caveira?

Nívia imita um monstro, alterando sua voz, o que faz as crianças rirem.

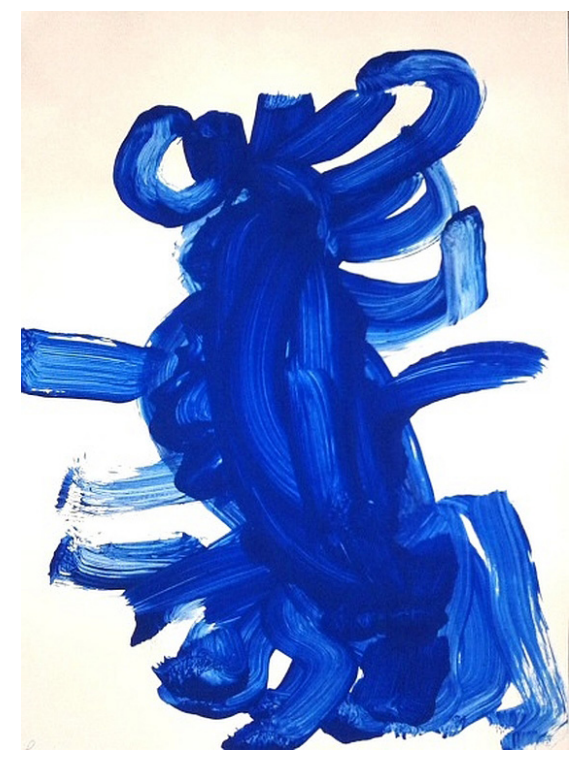

Figura 04: Desenho de Nívia: livro O domador de monstros. Fonte: Arquivos da pesquisadora.

Neste episódio, Nívia cria uma nova história a partir da contada, ao descrever seu desenho. Atribui novas características ao monstro, inclusive inventando onde mora. 
Esta e as demais narrativas das crianças mostram o potencial criativo que a literatura infantil pode desencadear/colaborar para sua constituição; entretanto, essa dinâmica de relações entre a narrativa (apresentada no texto e nas imagens) e a capacidade de inventar, acrescentar e/ou suprimir elementos não é automática; a oportunidade de retomar os textos, em memórias compartilhadas com os colegas e com a pesquisadora parece ser decisiva para que essas elaborações tenham possibilidade de acontecer.

Pesq.: E como é que foi o final da história?

Rafael: Eu lembro.

Pesq.: Então conta, Rafael.

Rafael fala muito baixo e não dá para entender. Diz algo sobre a personagem ir à escola. Pesq.: Por quê? Ele não ia à escola antes?

Rafael: Era mal educado.

$[\ldots]$

Pesq.: Então, vamos desenhar? Cada um desenha a parte que mais achou legal da história... O personagem que achou mais legal...

Rafael: Pode inventar?

Pesq.: Pode inventar uma parte que não existia na história.

As crianças escolhem as cores de giz de cera que irão utilizar e começam seus desenhos. (Entrevista 014)

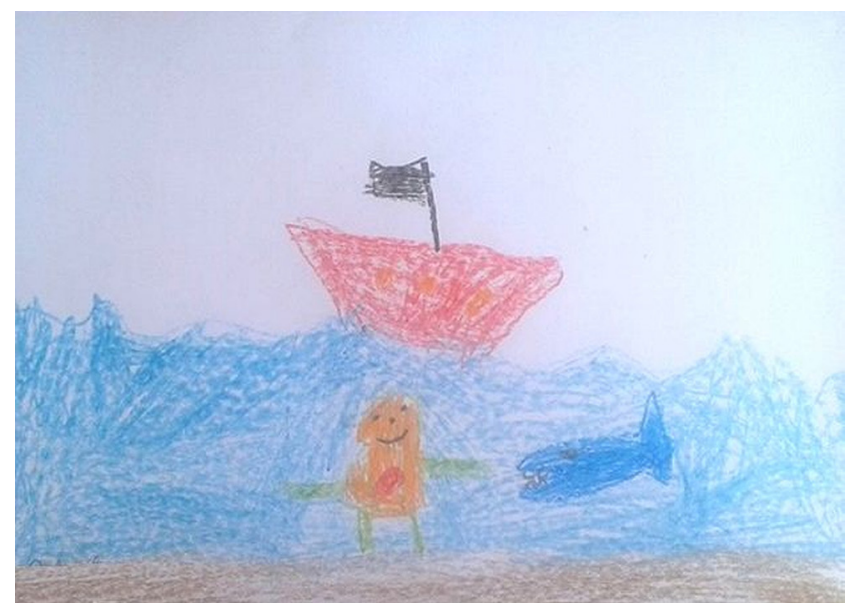

Figura 05: Desenho de Rafael: livro A escolinha do mar. Fonte: Arquivos da pesquisadora. 
Mesmo perguntando se poderia inventar e sendo autorizado a fazê-lo, Rafael produz seu desenho bastante próximo à história, incluindo dois personagens (Dona Ostra e Tubaronete), embora dê destaque ao barco, figura que no livro aparece em tamanho diminuto. No entanto, o que nos interessa, mais especificamente, é que ele, assim como outras crianças, vê esse momento pós-leitura, em que se configuram as entrevistas, como um momento no qual é permitido criar. Rafael pergunta para a pesquisadora se ele poderia inventar, possivelmente, por ver que outros colegas em outras oportunidades (especificamente nesses momentos de entrevista) inventaram, e não foram censurados.

A partir deste ponto, queremos ressaltar que essa dinâmica marcante dos momentos de elaborações, tendo o texto como referência, contrasta fortemente com os objetivos postos pela apostila para o trabalho a partir do texto. Apresentamos, a seguir, a atividade tendo o texto como pretexto no caso do livro A escolinha do mar.

A apostila indica que a leitura deve ser realizada pela professora e, em seguida, ela deverá solicitar que as crianças participem da sessão “Trocar ideias”, na qual os autores do material levantam estas perguntas sobre o livro: você acha que a história foi criada pela autora ou aconteceu de verdade? Onde se passa essa história? Quem são as personagens? O que o Tubaronete fez que deixou Dona Ostra triste?

Além dessas perguntas, no início da leitura, Neusa pôs às crianças outras questões, quando lhes mostrou apenas a capa do livro, para que elaborassem hipóteses sobre a história que seria lida.

Neusa: [...] Vocês acham que essa história se passa aonde?

Algumas crianças respondem: No mar.

Neusa: É na floresta?

Crianças: Não!

Neusa: Por que vocês acham que não é na floresta?

(silêncio)

Neusa, mostrando a capa: Tem floresta aqui?

Crianças: Não...

Neusa: Como que vocês sabem que é no mar? O que é que tem aqui?

Algumas respondem "tubarão", outras, "peixe".

Neusa: Onde fica o peixe?

Vários respondem: $N a$ água. 
Como podemos ver, as perguntas da apostila, assim como as elaboradas pela professora, seguem o padrão de busca de informações no trabalho com a história. As respostas esperadas não podem/devem ser criativas, havendo, claramente, respostas certas ou erradas. A tendência das crianças é de apresentar respostas bem simples, como "não", "peixe" etc. Este padrão de perguntas e respostas segue desta forma durante a leitura do texto:

Neusa: [...] Ele arrancou da dona Ostra. Quem sabe o que é que tem dentro da ostra? Algumas crianças respondem: Pérola!

O objetivo da apostila, com a indicação dessa leitura, é que ela sirva de base para as atividades subsequentes. A seguir, as duas páginas iniciais dessas atividades:

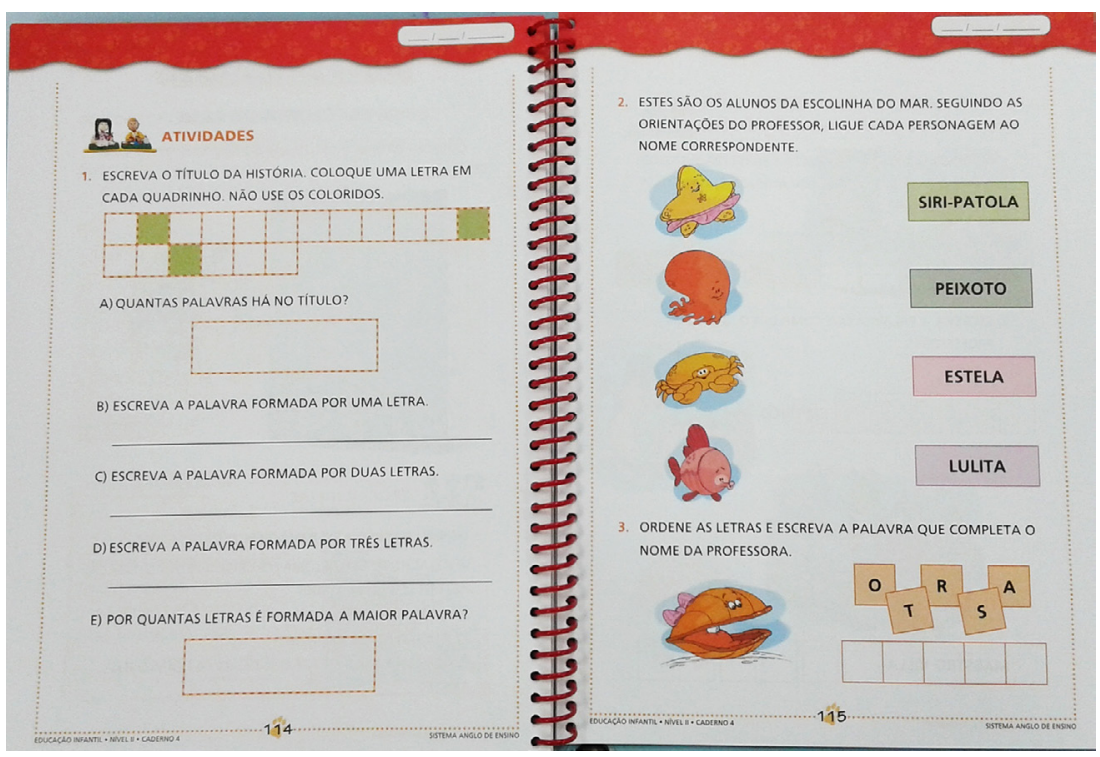

Figura 06: Apostila: primeiras páginas de atividades do livro A escolinha do mar. Fonte: Arquivos da pesquisadora.

Como podemos constatar, as atividades têm como propósito trabalhar princípios básicos de alfabetização e matemática, em seus seguintes elementos: as letras, as palavras, os números, as quantidades e os problemas matemáticos; questões do texto e 
da história em si são pouco exploradas e o imaginário, a criatividade ou o rememorar a história não são focos propostos para o trabalho pedagógico. Ou seja, nessas atividades não há espaço para o crescente interesse - registrado nas entrevistas - em criar, inventar, fazer novas elaborações a partir do conteúdo dos livros trabalhados.

Tendo em conta a tipologia proposta por Geraldi (2002) quanto aos distintos modos de trabalhar com a literatura em espaços escolares, podemos considerar que as entrevistas partem do texto como pretexto, para conversas e para a produção de desenhos. Entretanto, nos resultados de nossa pesquisa, o trabalho do texto como pretexto - mas não a ponto de apagar a importância da história lida - se mostrou, prioritariamente, mais enriquecedor no processo de interpretação e de criação das crianças sobre/a partir das histórias. Porém, esse modo de trabalho com a literatura exige tempo, abertura a respostas inusitadas, aos caminhos que se constroem a partir do argumento da narrativa. Há certa imprevisibilidade no trabalho realizado dessa forma. As conversas e os desenhos produzidos nas entrevistas foram sendo tecidos de maneiras variáveis, inclusive em termos de duração e do grau de envolvimento dos participantes. Essas peculiaridades de cada encontro precisam ser respeitadas e são um contraponto ao trabalho regrado, no ritmo imposto pelas apostilas.

Dessa forma, argumentamos que momentos como esses concretizados na entrevista - conversas em roda e em pequenos grupos e produção de desenhos sobre o livro - podem promover o desenvolvimento psicológico e social das crianças, por gerar oportunidades de discussão, reflexão, compreensão/(re)significação de assuntos do cotidiano, provocados pelas histórias, além do exercício da imaginação e da criatividade.

\section{CONSIDERAÇões Finais}

As particularidades das vivências de cada criança são a base da diversificação para suas interpretações e significações. Porém, essas interpretações e significações estão fortemente relacionadas aos modos como a mediação do adulto é realizada, tecendo-se, nas interações, a complexa rede pelas quais ambos - criança e adulto se relacionam com os atos de leitura e com os livros em si. O incentivo à imaginação e à atividade criadora dentro da escola é potencialmente uma tarefa da professora e dos profissionais que trabalham diretamente com as crianças (bibliotecária, monitora e demais professores). Entretanto, não raras vezes, sobretudo os professores são premidos a privilegiar a quantidade de trabalhos e não sua qualidade. 
No desenvolvimento do trabalho investigativo, ao contrário disso, a mediação da pesquisadora foi no sentido de permitir, possibilitar e incentivar que essas novas elaborações criativas diante do texto fossem concretizadas. Essas ações tiveram progressivos efeitos sobre os modos pelos quais os alunos foram produzindo suas elaborações, e é preciso lembrar que, quanto mais se tece em cima de um mesmo material, maiores as possibilidades de ele se tornar matéria-prima para outras produções, de ser internalizado.

A quantidade de livros não é sinônimo de qualidade na constituição de novos leitores, fortemente vinculada a sucessivas experiências irrepetíveis com o mesmo texto, pois, a cada gesto de leitura, novas significações podem ser produzidas, em especial pela oportunidade de compartilhar com o outro o que cada criança/leitor elege como pontos dignos de destaque.

Ampliar a experiência não significa apenas diversificar e oferecer a maior quantidade possível de histórias para a criança. A ampliação da experiência também pode ser feita pelo aprofundamento de elaborações sobre elas, pela oportunidade de criar novas relações, conforme pudemos acompanhar as crianças realizando em muitos pontos das entrevistas. Ao longo da pesquisa, pudemos perceber uma mudança positiva no que diz respeito à participação das crianças nas entrevistas. Foi possível constatar que, não raras vezes, as imagens do livro, mais do que o texto e a história em si, capturavam sua atenção, oferecendo pequenos detalhes significativos a elas. Esse trabalho interpretativo do leitor (no caso da pesquisa realizada, das crianças) tem importante papel nas elaborações coletivas, em que se partilham leituras singulares. Ou seja, permite que cada criança possa ver o que o outro viu, ressaltar e validar aspectos levantados pelos colegas e/ou contradizê-los e argumentar quando as posições não são confluentes. Dessa forma, parece-nos que considerar estas peculiaridades pode ser importante passo para a organização do trabalho pedagógico com a literatura na Educação Infantil.

\section{REFERÊNCIAS}

ALMEIDA, Tatyane A.; GOMES, Maria de F. C.; MONTEIRO, Sara M. Aprendizagem e desenvolvimento de crianças de seis anos na roda de história. Educação \& Realidade, Porto Alegre, v. 38, n. 4, p. 1303-1326, out./dez. 2013.

ARENA, Dagoberto B.; LOPES, Naiane R. PNBE 2010: personagens negros como protagonistas. Educação \& Realidade, Porto Alegre, v. 38, n. 4, p. 1147-1173, out./dez. 2013. Disponível em: <http:// www.seer.ufrgs.br/index.php/educacaoerealidade/article/view/38158>. Acesso em: 16 ago. 2015. 
CRUZ, Carlos M. da. A leitura como fruição do texto no âmbito escolar e a formação de leitores. Cadernos do CNLF, Rio de Janeiro, v. XVI, n. o4, t. 3. Anais do XVI Congresso Nacional de Linguística e Filologia. Rio de Janeiro: CiFEFiL, 2002. p. 2760-2767.

FONSECA, Maria N. G. da; GERALDI, João W. O circuito do livro e a escola. In: GERALDI, João Wanderley (Org.). O texto na sala de aula. São Paulo-SP: Ática, 2002. p. 104-114.

FREITAS, Maria T. A. A perspectiva sócio-histórica: uma visão humana da construção do conhecimento. In: FREITAS, M. T. A.; SOUZA, S. J.; KRAMER, S. Ciências Humanas e Pesquisa: leituras de Mikail Bakhtin. São Paulo: Cortez, 2007. p. 21-40.

GERALDI, João W. Prática de leitura na escola. In: GERALDI, João Wanderley (Org.). O texto na sala de aula. São Paulo-SP: Ática, 2002. p. 82-87.

MONTEIRO, Vera. Promoção do autoconceito e autoestima através de um programa de leitura a par. Psicologia: Reflexão e Crítica, Porto Alegre, v. 25, n. 1, p. 147-155, 2010. Disponível em: <http:// www.scielo.br/pdf/prc/v25n1/a18v25n1.pdf >. Acesso em: 16 ago. 2015.

OLIVEIRA, Eliane R. de Oliveira; CALDIN, Clarise F.; SILVA, Patrícia V. Biblioterapia para crianças em idade pré-escolar: estudo de caso. Perspectivas em Ciência da Informação, Belo Horizonte, v. 11 n.3, p. 398-415, set./dez. 2006. Disponível em: <http://www.scielo.br/pdf/pci/vi1n3/ao8vi1n3. pdf $>$. Acesso em: 16 ago. 2015 .

PORCACCHIA, Sonia S.; BARONE, Leda M. C. Construindo leitores: uma experiência de oficina de leitura. Estudos de Psicologia, Campinas, v. 28, n. 3, jul./set. 2011.

PRADO, Patrícia D. Os três porquinhos e as temporalidades da infância. Cad. Cedes, Campinas, v. 32, n. 86, p. 81-96, jan./abr. 2012. Disponível em: http://www.scielo.br/pdf/ccedes/v32n86/ v32n86ao6.pdf. Acesso em: 16 ago. 2015.

RODRIGUES, Marisa C.; HENRIQUE, Mariana W.; PATRÍCIO, Marina O. Leitura de histórias e evocação de estados mentais por pré-escolares. Psicologia Escolar e Educacional, Campinas, v. 13, n. 1, p. 37-44, jan./jun. 2009.

SILVA, Lilian L. M. Às vezes ela mandava ler dois ou três livros por ano. In: GERALDI, João Wanderley (Org.). O texto na sala de aula. São Paulo-SP: Ática, 2002. p. 82-87.

SILVA, Paulo V. B. da; SOUZA, Gizele de. Relações étnico-raciais e práticas pedagógicas em Educação Infantil. Educar em Revista, Curitiba, Brasil, n. 47, p. 35-50, jan./mar. 2013. Disponível em: <http://www.scielo.br/pdf/er/n47/o4.pdf >. Acesso em: 16 ago. 2015.

WITTER, Geraldina P.; RAMOS, Oswaldo A. Influência das cores na motivação para leitura das obras de literatura infantil. Psicologia Escolar e Educacional, Campinas, v. 12, n. 1, jun. 2008.

XAVIER FILHA, Constantina. Era uma vez uma princesa e um príncipe...: representações de gênero nas narrativas de crianças. Estudos Feministas, Florianópolis, p. 591-603, maio/ago. 2011. Disponível em: <http://www.scielo.br/pdf/ref/v19n2/v19n2a19.pdf>. Acesso em: 16 ago. 2015.

\section{SOBRE AS AUTORAS}

Larissa Elizabeth de Barros Brito é graduada em Educação Artística (Centro Universitário Nossa Senhora do Patrocínio) e em Pedagogia (Faculdade Max 
Planck) e mestre em Educação (Pontifícia Universidade Católica de Campinas). Atualmente é professora de arte no Colégio Renovação, no Colégio Rodin e na Escola Algodão Doce. Tem experiência na área de Educação, atuando principalmente como arte educadora.

E-mail: lebbrito@gmail.com

Maria Sílvia Pinto de Moura Librandi da Rocha possui Graduação em Psicologia e Graduação em Licenciatura em Psicologia (Pontifícia Universidade Católica de Campinas). Tem aprimoramento em Psicopedagogia (Universidade de São Paulo, Ribeirão Preto), Mestrado e Doutorado em Educação (Universidade Estadual de Campinas) e Pós-Doutorado em Psicologia e Educação (Universidade de Barcelona). Atualmente é docente do Programa de Pós-Graduação em Educação da Pontifícia Universidade Católica de Campinas. É líder do Grupo de Pesquisa Formação e Trabalho Docente, em que são desenvolvidos trabalhos na Linha de Pesquisa "Formação de Professores e Práticas Pedagógicas", principalmente nos seguintes temas: desenvolvimento psicológico infantil, funções psicológicas superiores, atividade lúdica, alfabetização e letramento, relacionando-os com práticas pedagógicas e formação de professores da Educação Infantil e do Ensino Fundamental (anos iniciais).

E-mail: silrocha@uol.com.br 